\title{
Donor Site Evaluation After Lingual Mucosal Graft Harvest for Urethroplasty
}

\author{
M Asaduzzaman ${ }^{1}$, MR Quddus $^{2}$, MS Islam $^{3}, \mathrm{~K}$ Ahmed $^{4}$ \\ SK Rosy ${ }^{5}$, AKMZI Bhuiyan ${ }^{6}$ \\ ${ }^{1}$ Dept of Transplant Surgery, National Institute of Kidney Diseases and Urology, (NIKDU), Dhaka \\ ${ }^{2}$ Dept of Surgery, Satkhira Sadar Hospital, Satkhira \\ ${ }^{3}$ Dept of Urology, National Institute of Kidney Diseases and Urology, (NIKDU), Dhaka \\ ${ }^{4}$ Surgery Outpation Department, Sir Salimullah Medical College and Mitford Hospital, Dhaka \\ ${ }^{5}$ Raypur Union Subcentre, Barhatta, Netrokona \\ ${ }^{6}$ Dept of Urology, National Institute of Kidney Diseases and Urology, (NIKDU), Dhaka
}

\begin{abstract}
This study was carried out in the Department of Urology, National Institute of Kidney Diseases and Urology, (NIKDU), during the period from Jan' 09 to Dec' 10 to assess the complications at donor site after lingual mucosal graft harvesting for urethroplasty. A total of 30 patients with mean age of 36.6 years (rang 21 to 56 years) and mean urethal stricture length of $36 \mathrm{~mm}$ (range 22 to $59 \mathrm{~mm}$ ) who underwent urethroplasty for anterior urethral strictures using dorsal onlay of a lingual mucosal graft (LMG) were selected for the study. The site of the harvest graft was ventrolateral mucosal lining of the tongue. Donor site complications like pain, numbness, tightness, slurring of speech, salivatory changes and difficulty in protrusion of tongue were noted. The mean period of follow-up was 14 months (range 6-18 months). At the first postoperative day, 96\% of the patients experienced pain at donor site and $26 \%$ had slurring of speech. Pain was mild to discomforting in $60 \%$ and distressing to excruciating in $37 \%$ of the patients. By third postoperative day, $22(73 \%)$ patients were pain free, $06(20 \%)$ suffered from mild pain and $02(6 \%)$ suffered from discomforting pain only and none had slurring of speech. On the fifth postoperative day, only $02(6 \%)$ patient suffered pain. By day 6 of surgery, all patients were pain free. Only $01(3.3 \%)$ patients reported numbness which persisted during the whole period of follow up. The study showed that LMG is easy to harvest and associated with less postoperative pain, minor risk of donor site complications and without any functional or esthetic deficiency. So tongue may be the best alternative donor site for anterior urothroplasty.
\end{abstract}

Key words: Lingual mucosa, Urethral stricture, Urethroplasty

\section{Introduction}

Anterior urethral strictures are common in routine urological practice. There is a wide variety of options for managing anterior urethral strictures starting from urethral dilatation to substitution urethroplasty for long strictures. Since the 1990s, a large variety of free extragenital graft tissues have been used for urethroplasty, such as the ureter, saphenous vein, appendix, full-thickness skin, bladder mucosa, and buccal mucosa ${ }^{1}$. Currently, buccal mucosal graft (BMG) provides excellent clinical results but may also cause oral complications ${ }^{2-6}$. The main long-term complications are perioral numbness, persistent difficulty with mouth opening and change in salivary function ${ }^{7}$. The complications of lip mucosal graft harvesting are eversion of lip vermilion and lip contracture ${ }^{8}$. Simonato et al. first used tongue tissue as an alternative donor site in graft urethroplasty9. Lingual mucosa has constant availability, easy 
harvesting, and favorable immunologic properties (resistance to infection) and tissue characteristics i.e a thick epithelium, high content of elastic fibers, thin lamina propria, and rich vascularization and it is not hairy ${ }^{10}$. The use of lingual mucosal graft (LMG) for the anterior urethroplasty is well tolerated and effective in patients with anterior urethral strictures requiring surgery. So the study was designed to use lingual mucosal graft (LMG) for the management of anterior urethral strictures and evaluated the possible complication at the donor site in our population.

\section{Materials and Methods}

This descriptive study was conducted in the Department of Urology, National Institute of Kidney Diseases and Urology, (NIKDU), Dhaka during the period form Jan' 09 to Dec'10 for which 30 men with mean age of 36.6 years, range being 21 to 50 years were selected for single stage dorsal onlay urethroplasty with LMG. Stricture length was 22 to $59 \mathrm{~mm}$ (mean $36 \mathrm{~mm}), 14$ strictures were in the bulbar urethra, 09 were in the proximal penile and 07 were in both bulber and penile urethra. All patients were evaluated preoperatively with uroflowmetry, urethroscopy, retrograde and voiding urethrography. The oral cavity of all patients planned for substitution urethroplasty was inspected. Exclusion criteria include stricture length $<2 \mathrm{~cm}$, leucoplakia of oral cavity, submucosal fibrosis and any history of previous oral surgery or oral neuropathy. Patients were started on Povidone-iodine mouth gargles thrice daily, 48 hours before surgery.

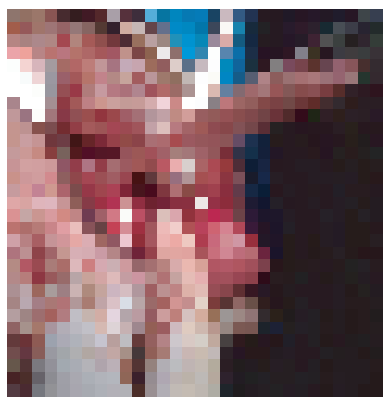

Figure-2
Table I: Patient characteristics

$$
\text { No. patients Mean }
$$

\begin{tabular}{lll}
\hline Age of the patient (years) & 30 & 36.6 (years) \\
22-56 & & \\
Aetiology of stricture & 21 & \\
$\quad$ Balanitis Xerotica Obliterans & 4 & \\
Inflammatory & 1 & \\
Iatrogenic & 1 & \\
$\quad$ Traumatic & 3 & \\
$\quad$ Idiopathic & & \\
Length of stricture (mm) & 19 & $36(\mathrm{~mm})$ \\
22-50 & 11 & \\
More than 50 & & \\
Site of stricture & 09 & \\
$\quad$ Penile urethra & 14 & \\
Bulbar urethra & 7 & \\
$\quad$ Penobulbar urethra & & \\
Previous stricture treatment & 10 & \\
$\quad$ Urethral dilatation & 10 & \\
Optical internal urethrotomy & 7 & \\
Meatotomy & 3 & \\
Meatoplasty &
\end{tabular}

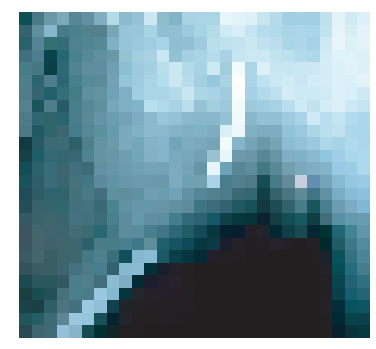

Figure-.1 Before Operation

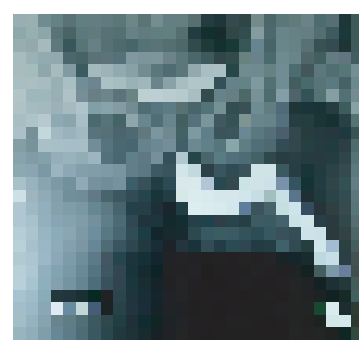

After Operation
Harvesting and preparation lingual mucosal graft:

The surgical procedures performed under general anesthesia with endotracheal intubation by a team of urologist. A standard mouth opener was put into place. The apex of the tongue was passed through via a stitch for traction outside of the mouth to expose the
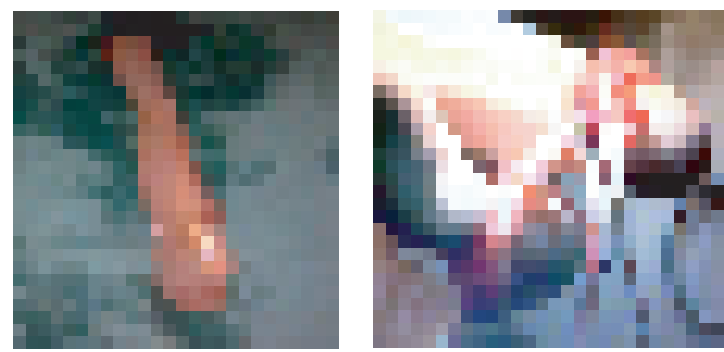
ventrolateral surface of the tongue. Grafts were harvested from the ventral to lateral mucosal lining of the tongue. The required graft was measured. The graft was harvested unilaterally from the tongue, if large graft required then harvested bilaterally from the tongue. The harvest graft site was infiltrated with a mixed solution of $1 \%$ lignocaine with 1:100000 adrenaline. The graft edges

were incised and a full-thickness mucosal graft was harvested using a sharp knife beginning at the anterior landmark of the graft. The donor site bed was carefully examined for bleeding and was closed using 4-0 polyglactin running sutures. In all patients dorsal free graft urethroplasty as described by Barbagli et al. was carried out 11,12 .

\section{Postoperative Management and Follow-up:}

Patients were given injection Ketorolac $30 \mathrm{mg}$ twice a day on the day of surgery and from postoperative day 1, all patients received tablet Ketorolac $10 \mathrm{mg}$ twice daily as pain medication and continued with Povidone-iodine mouth gargles. Nutrition was left to the desire of the patient with no restriction on food and no special diet was given. A well-validated simple McGill pain questionnaire in which score is described in words (Table 2) was used to assess postoperative pain at the donor site. Patients were routinely discharged 7-8 days after the surgery and any complaint citied by the patient were noted. Follow up at 3rd week, at 3rd month and at 6th month of all patients on outpatient basis were carried out. Patients were also asked if they would be happy to have the graft harvested from lingual mucosa again, even if there were suitable alternatives and if they would recommend this operation to their families and friends.

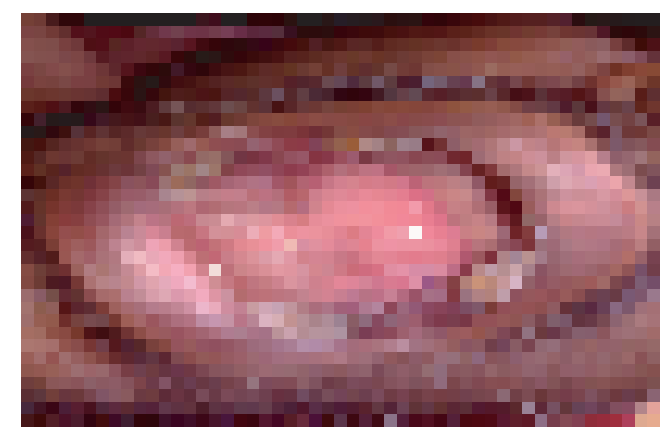

Figure-3. Postoperative

\section{Results and Observations}

The mean follow-up time was 14 months (range 6-18 months). A total of 32 patients with anterior urethral stricture included in this study according to the selection criteria. Two patients were lost during follow up. Therefore, a total of 30 patients were taken for final assessment. After complete explanation, all patients in postoperative period were given the pain score questionnaire twice daily at 10.00 hours and 20.00 hours and asked to complete it.

Table II: Pain scoring scale

Present pain intensity of the standard long form McGill pain Questionnaire

0 No pain

1 Mild pain

2 Discomforting

3 Distressing

4 Horrible

\section{Excruciating}

A total of $29(96 \%)$ patients experienced pain at the donor site on 1 st postoperative day. Pain was mild in 06 (20\%), discomforting in 12 (40\%), distressing in $02(6 \%)$, horrible in $07(23 \%)$ and Excruciating in $02(6 \%)$ patients. By third postoperative day, $22(73 \%)$ patients were pain free, $06(20 \%)$ suffered from mild pain and 02 (6\%) suffered from discomforting pain only. On the fifth postoperative day, only 02 (6\%) patients suffered from pain. By sixth postoperative day, no patient reported pain at donor site. Slurring of speech was observed in $07(23 \%)$ patients for 2 days but at 3rd week, at 3rd month and at 6th month follow up no slurring of speech in any patient. Follow up at first 48 hours and at 3rd week numbness were present in $4(13.3 \%)$ patients but at 3rd month and 6th month follow up numbness present in 01(3.3) patients respectively. Follow up at first 48 hours, at 3rd week, at 3rd month and at 6th month no tightness were present in any patient. 
Healing at donor site was excellent with no bleeding, hematoma or infection. All the patients were able to resume oral fluids within 24 hours, ate soft solids in $48-72$ hours and return to normal diet within 4-5 days of surgery (Fig-4). None of the patient suffered injury to the sublingual salivary glands during surgery. No patient suffered from difficulty in opening the mouth, salivation disturbances or difficulty in protrusion of tongue. In response to a question whether patients would have his lingual mucosa harvested again if required in $83.3 \%$ were satisfied, $10.0 \%$ no and $6.7 \%$ had mixed feelings.

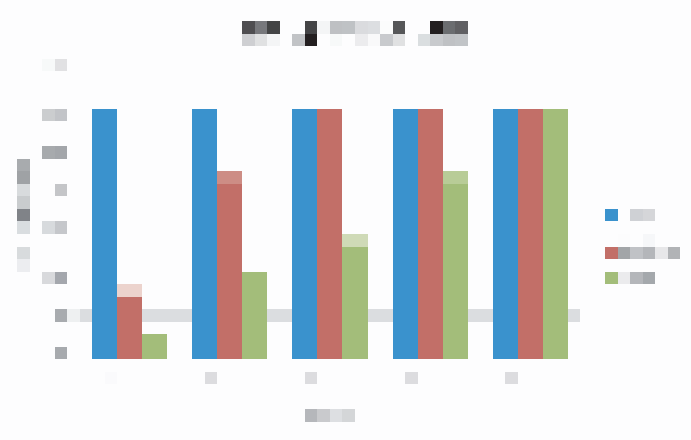

\section{Discussion}

The identification of autologus material for replacing the urothelium in urethral reconstruction is an open challenge. Since the first reported use of buccal mucosa in urethroplasty for adults by EL-Kasaby et al. increasingly many urologists are using $i^{13}$. Indeed since 1995, cheek mucosa has been used more often than penile skin $^{14}$. Buccal mucosa gives excellent results ${ }^{15}$. Other advantages of buccal mucosa as a free graft are that it is hairless and has a thick elastic rich epithelium making it tough and easy to handle. However, it is not without complication. Substitution urethroplasty is the mainstay of the management for long anterior urethral strictures. Though buccal mucosal graft (BMG) is the gold standard, at present, studies have been published using LMG with equal efficacy but less donor site morbidity.

Simonato et al. first described the use of tongue tissue as an alternative donor site in graft urethroplasty ${ }^{9}$. Barbagli et al. showed that use of lingual mucosal graft for the anterior urethroplasty is well tolerated and effective in patients with urethral strictures requiring surgery ${ }^{16}$.

The mucosa covering the ventrolateral aspect of the tongue is identical in structure with that lining the rest of the oral cavity. Kumar et al. found that, as with buccal mucosa, lingual mucosa has constant availability, easy harvesting, and favorable immunologic properties (resistance to infection) and tissue characteristics i.e. a thick epithelium, high content of elastic fibers, thin lamina propria, and rich vascularization, and it is not hairy 9,16 .

The present study showed most patients complained of pain on oral cavity. $96 \%$ of patients (29 out of 30 patients) experienced pain at the donor site on 1st postoperative day (POD). Pain was mild in 06 (20\%), discomforting in $12(40 \%)$, distressing in 02 $(6 \%)$, horrible in $07(23 \%)$ and excruciating in $02(6 \%)$ patients. By third postoperative day, $22(73 \%)$ patients were pain free, $06(20 \%)$ suffered from mild pain and two (6\%) suffered from discomforting pain only. On the fifth postoperative day, only $02(6 \%)$ patients suffered from pain. By sixth postoperative day, no patient reported pain at donor site. Kumar et al. also reported simillar findings regarding pain at donor site on 6 th post operative day ${ }^{17}$. Kumar et al. also showed $90 \%$ of patients ( 28 of 30 patients) experienced pain at the donor site on first postoperative day. Pain was mild in $07(23 \%)$ patients, discomforting in $17(56.6 \%)$ patients and distressing and horrible in 02 (6.6\%) patients respectively10. Simonato et al. showed just slight oral discomfort within the first to third postoperative day 9 .

In lingual mucosal graft urethroplasty $13.3 \%$ (4/30) patients complained of perioral numbness at $2^{\text {nd }}$ POD and follow up at $3^{\text {rd }}$ week and numbness was present in $04(13.3 \%)$ patients but follow up at $3^{\text {rd }}$ month and $6^{\text {th }}$ month only $01(3.3 \%)$ patient complaint of perioral numbness. Kumar et al. and $\mathrm{Xu}$ et al. showed $02(6.6 \%)$ patients reported perioral numbness persisted in the first follow up after 1 month and subsided by the second, minor 
numbness was reported in $33.7 \%$ (31/92) patients in one week, $18.39 \%(16 / 87)$ patients in 6 months respectively ${ }^{10,18}$. Kumar et al. and Das et al. showed no perioral numbness ${ }^{10,19}$. No patient compliant of tightness in oral cavity. Kumar et al., Das et al. and $\mathrm{Xu}$ et al. showed no tightness in oral cavity ${ }^{10,18-19}$. In lingual mucosal graft urethroplasty $23.3 \%$ (7/30) patients complained of slurring of speech at $2^{\text {nd }}$ POD but no patient complained of slurring of speech from next follow up. Kumar et al., Das et al. and Xu-min et al. showed no complain of slurring of speech ${ }^{10,18-19}$.

In this study it was observed that the mucosa of the tongue, which is identical to the mucosa of the rest of the oral cavity, is a safe and effective graft material in the armamentarium for urethral reconstruction with potential minor risks of donor site complications.

Buccal mucosa is a good material for urethroplasty but the harvesting procedure is not without morbidity. Lingual mucosal graft (LMG) harvesting is feasible, provides long grafts and is easy to carry out. LMG has minimal immediate or short-term donor site complications with no long-term adverse effects. Patients seem to be able to accept it with satisfactory functions and aesthetic aspect of the donor site. Thus it is the ideal free graft for urethroplasty with no donor site complications. Therefore, lingual mucosal graft urethroplasty should be preferred to buccal mucosal in anterior urethral stricture.

\section{References}

1. Dessanti A, Rigamonti W, Merulla V. Autologous buccal mucosa graft for hypospadias repair: An initial report. J Urol 1992; 147: 1081-1084.

2. Andrich DE and Mundy AR. Substitution urethroplasty with buccal mucosal free grafts. J Urol 2001; 165: 1131.

3. Wessells H. Ventral onlay graft techniques for urethroplasty. Urol Clin North Am 2001; 29: 381.

4. Heinke T, Gerharz EW, Bonfig R, Riedmiller H. Ventral onlay urethroplasty using buccal mucosa for complex stricture repair. Urology 2003; 61: 1004.

5. Pansadoro V, Emiliozzi P, Gaffi M, Scarpone $P$, DePaula F, Pizzo M. Buccal mucosa urethroplasty in the treatment of bulbar urethral strictures. Urology 2003; 61: 1008 .
6. Dublin N and Stewart LH. Oral complications after buccal mucosal graft harvest for urethroplasty. BJU Int 2004; 94: 867.

7. Wood DN, Allen SE, Andrich DE, Green Well TJ, Mundy AR. The morbidity of buccal mucosal graft harvest for urethroplasty and the effect of nonclosure of the graft harvest site on postoperative pain. J Urol 2004; 172: 580-83.

8. Eppley BL, Keating M, Rink R. A buccal mucosal harvesting technique for urethral reconstruction. J Urol 1997; 157:1268-70.

9. Simonato A, Gregori A, Lissiani A, Galli S, Ottaviani F, Rossi R. The tongue as an alternative donor site for graft urethroplasty: a pilot study. J Urol 2006; 175 : 589-92.

10. Kumar A, Goyal NK, Das SK, Trivedi S, Dwivedi US, Singh PB. Oral complications after lingual mucosal graft harvest for urethroplasty. ANZ J Surg 2007; 77: 970-973.

11. Barbagli G. Dorsal free graft urethroplasty. J Urol 1996; 155: 123-6.

12. Iselin CE and Webster GD. Dorsal onlay graft urethroplasty for repair of urethral stricture. J Urol 1999;161:815-8.

13. EL-Kasaby AW, Fath-Alla M, Noweir AM, E1Halaby MR, ZakariaW, EL-Beialy MH. The use of buccal mucosa patch graft in the management of anterior urethral strictures. J Urol 1993; 149: 276-8.

14. Wessells H. Ventral onlay graft techniques for urethroplasty. Urol Clin N Am 2002; 29: 381-7.

15. Morey AF and McAninch JW. Technique of harvesting buccal mucosa for urethral reconstruction. J Urol 1996; 155: 1696-7.

16. Barbagli G, De Angelis M, Romano G, Ciabatti PG, Lazzeri M. The use of lingual mucosal graft in adult anterior urethroplasty: surgical steps and short-term outcome. Eur Urol 2008; 54: 671-6.

17. Kumar A, Das SK, Sharma GK, Pandey AK, Trivedi $S$, Dwivedi US. Lingual mucosal graft urethroplasty for anterior urethral strictures: Our technique of graft harvesting. World J Urol 2008; 26: 275-80.

18. Xu YM, Qiang FU, Ying-long SA, Zhang J, Jin CR, Jie-min SI, Song LJ. Treatment of urethral strictures using lingual mucosa urethroplasty: experience of 92 cases. Chin Med J 2010; 123: 458-462.

19. Das SK, Kumar A, Sharma GK, Pandey AK, Bansal H, Trivedi S, Dwivedi US. Lingual mucosal graft urethroplasty for anterior urethral strictures. Urology 2009; 73: 105-108. 